\title{
Characteristics and Healthcare Costs in the Aging Hepatitis B Population of Japan: A Nationwide Real-World Analysis
}

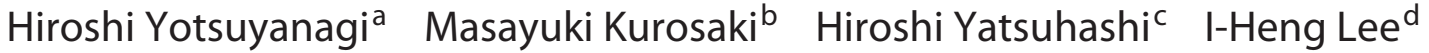 \\ Alvin $\mathrm{Ng}^{\mathrm{e}}$ Craig Brooks-Rooney ${ }^{\mathrm{f}}$ Mindie H. Nguyeng \\ aDepartment of Infectious Diseases and Applied Immunology, The Hospital of The Institute of Medical Science, \\ The University of Tokyo, Tokyo, Japan; 'bepartment of Gastroenterology and Hepatology, Japanese Red Cross \\ Musahino Hospital, Tokyo, Japan; 'CClinical Research Center, National Hospital Organization Nagasaki Medical \\ Center, Nagasaki University Graduate School of Biomedical Sciences, Nagasaki, Japan; ${ }^{\mathrm{d} G i l e a d}$ Sciences Inc., Foster \\ City, CA, USA; ${ }^{e}$ Costello Medical Singapore Pte Ltd, Singapore, Singapore; ${ }^{f}$ Costello Medical, Boston, MA, USA; \\ gDivision of Gastroenterology and Hepatology, Stanford University Medical Center, Palo Alto, CA, USA
}

\section{Keywords}

Chronic hepatitis B - Comorbidity - Epidemiology · Healthcare administrative claims · Kidney diseases . Osteoporosis

\begin{abstract}
Introduction: Advancing age, comorbidity, and financial burden have been observed in chronic hepatitis $B$ (CHB) patients globally. As Japan is leading the world in aging demographics, similar real-world data are urgently needed for its CHB population to inform all stakeholders. Methods: This cross-sectional study characterized the demographics, comorbidities, and healthcare costs of a large Japanese realworld adult ( $\geq 18$ years) CHB patient (ICD-10: B18.1) population from the Medical Data Vision database from January 01, 2012, to December 31, 2016. Comorbidities were identified by ICD-10 codes, and the annual point prevalence and Charlson Comorbidity Index (CCl) score were calculated. Annual mean and median all-cause healthcare utilization and costs per patient were calculated. Comparison tests were conducted for $\mathrm{CCl}$ scores, prevalence of comorbidities, and healthcare resource utilization and costs. Results: We identi-
\end{abstract}

karger@karger.com www.karger.com/ddi

Karger $\frac{1}{\%}$
(C) 2021 The Author(s)

Published by S. Karger AG, Basel

This is an Open Access article licensed under the Creative Common Attribution-NonCommercial-4.0 International License (CC BY-NC) (http://www.karger.com/Services/OpenAccessLicense), applicable to the online version of the article only. Usage and distribution for commercial purposes requires written permission. fied 11,125 CHB patients. Between 2012 and 2016, the mean age increased from 62.0 to 65.2 years, and the percentage of those aged $\geq 65$ years increased from $45.6 \%$ to $60.7 \%$. The prevalence of cirrhosis remained similar (5.8\% in 2012 and $5.6 \%$ in $2016, p=0.69$ ) while hepatocellular carcinoma decreased from $6.3 \%$ to $4.5 \%(p<0.01)$. The prevalence of nonliver comorbidities increased $(40.9-52.0 \%$ for cancer $[p<$ $0.01], 12.1-17.7 \%$ for osteoporosis $[p<0.01]$, and $10.7-15.0 \%$ for renal impairment $[p<0.01])$. Healthcare resource utilization and costs also increased, with a $119.3 \%$ increase in median total healthcare costs from JPY 229,143 in 2012 to 502,467 in $2016(p<0.01)$. Conclusions: The CHB population of Japan is predominantly elderly and carry a high nonliver comorbidity burden, while incurring increasing healthcare costs.

(C) 2021 The Author(s)

Published by S. Karger AG, Basel

\section{Introduction}

Chronic hepatitis B virus (HBV) infection leads to cirrhosis and hepatocellular carcinoma (HCC) and affected 257 million people worldwide in 2015 [1]. In Japan, the 
estimated prevalence of HBV infection was $0.6 \%$ in 2016 while the total estimated $\mathrm{CHB}$ population included 719,000 people [2]. In 2019, the estimated number of deaths attributed to HBV infection in Japan was between 6,475 and 8,750 [3].

In the year 2000, almost $80 \%$ of the total Japan CHB population were 40 years of age or older while in 2016, the prevalence of HBV infection in Japanese children was very low $(0.033 \%)$. These findings probably resulted from the institution of a selective program providing hepatitis B immune globulin and hepatitis B vaccination for infants born to hepatitis B surface antigen-positive mothers in 1986, since the Japanese government only introduced universal hepatitis B vaccination for infants in 2016 [4, 5].

This unique distribution of Japan's CHB population results from Japan having one of the highest life expectancy and the lowest birth rates in the world $[6,7]$. As the general population of Japan continues to age (36 million or $28 \%$ out of the total 126 million in 2019 being 65 years or older), the Japan CHB population is also likely to be aging [8]. Thus, the high proportion of elderly people in Japan highlights the importance of assessing and controlling healthcare utilization and expenditures in Japan, a country with the third largest economy and the eleventh most populous in the world [9-11].

Apart from the liver-related sequelae of $\mathrm{CHB}$, nonliver comorbidities are additional concerns that can complicate the clinical management of an aging $\mathrm{CHB}$ population. As recently shown by a healthcare claims database study in the USA, the mean age of the CHB population in the USA increased from 48 to 52 years between 2006 and 2015, with an increased prevalence of multiple comorbidities including cardiovascular diseases (CVD), diabetes, hyperlipidemia, renal impairment, and bone-related diseases alongside increased healthcare resource utilization and cost [12]. In addition, compared to age- and sex-matched non-CHB controls, $\mathrm{CHB}$ patients were found to have a higher cumulative incidence of chronic kidney disease, which was also observed in a prior study using the Taiwan National Insurance database [12-14]. However, data characterizing the real-world CHB population in Japan are limited.

Therefore, to assist clinical sectors in the management of the aging $\mathrm{CHB}$ population and inform other stakeholders to guide public health efforts and government resource allocation, we aimed to examine the demographics, prevalence of liver and nonliver comorbidities, healthcare resource utilization, and costs as well as their changes over time in a large nationwide real-world cohort of CHB patients in Japan using the Medical Data Vision database (MDV, Tokyo, Japan) [15].

\section{Materials and Methods}

\section{Study Design}

We performed a retrospective cross-sectional analysis of $\mathrm{CHB}$ patients in Japan using the MDV claims database from April 2008 to March 2017. Since 2008, the MDV database has collected monthly data on inpatient, outpatient, and pharmacy claims in addition to disease-procedure combination claims. As of 2017, the MDV database included approximately 300 hospitals (inclusive of acute inpatient care and routine outpatient ambulatory care), covering $>20$ million patients across Japan [15].

In our study, 2 subsets from the MDV database were used: Act data (containing information on treatment and procedures) and Disease data (containing information on diagnosed diseases). From these 2 datasets, we identified a total of 86,234 patients with CHB between April 2008 and March 2017. Data in this period were used to determine eligibility of patients; however, the analyses were conducted on data between January 2012 and December 2016. Data prior to 2012 were excluded due to small patient numbers, and data from 2017 were excluded as only the first 3 months of the calendar year were available.

\section{Study Population}

The study included adult patients who had at least 1 record of CHB (ICD-10: B18.1) and were aged 18 years or older at their index date, that is, date of the first visit with a $\mathrm{CHB}$ diagnosis. $\mathrm{Pa}$ tients were excluded if they had hepatitis $C$, hepatitis D, or human immunodeficiency virus coinfection; hepatitis $\mathrm{B}$ patients receiving interferon-based therapy were also excluded due to the potential for the treatment-related adverse events to skew the comorbidity and healthcare resource utilization analyses. Patients who received nucleot(s)ide analog therapy (whether treatment naïve or experienced at study entry) were eligible for inclusion. Patients must have had at least 1 claim for any disease, treatment, or procedure in the 6 months pre-index and post-index dates to ensure that patients included in the study accessed the healthcare system during the study duration. Online suppl. Table 1 (for all online suppl. material, see www.karger.com/doi/10.1159/000515854) describes further details of the inclusion and exclusion criteria of the study.

\section{Outcome Measures}

Outcome measures included demographic characteristics (gender and age), diagnoses of comorbidities by ICD-10 codes, total all-cause healthcare resource utilization, and healthcare costs. All analyses were summarized by the calendar year (2012-2016). Patients were included in each year if they had at least 1 claim in either Act data or Disease data in the years during or after the index date.

For the demographic analyses, we extracted gender and age from the sex and age variables, respectively. We reported mean age with standard deviation (SD) in each year. We also reported age groups based on the age at their index date or first claim in that particular year (18-34, 35-44, 45-54, 55-64, 65-74, and $\geq 75$ years) and gender distribution in percentages. Patients aged $\geq 65$ years were considered elderly [16].

We assessed the overall comorbidity burden of the study cohort via the Charlson Comorbidity Index (CCI) using ICD-10 codes for each patient from Disease data [17]. CCI scores can range from 0 to 28 , with a higher number indicating a poorer health state. CCI scores were summed and divided by the number of patients to cal- 
Table 1. Patient characteristics of the study population by calendar year

\begin{tabular}{|c|c|c|c|c|c|c|}
\hline \multirow[t]{2}{*}{ Parameter } & \multirow[t]{2}{*}{ Variable } & \multicolumn{5}{|c|}{ CHB population } \\
\hline & & $\begin{array}{l}2012 \\
(N=1,291)\end{array}$ & $\begin{array}{l}2013 \\
(N=2,253)\end{array}$ & $\begin{array}{l}2014 \\
(N=4,212)\end{array}$ & $\begin{array}{l}2015 \\
(N=6,435)\end{array}$ & $\begin{array}{l}2016 \\
(N=8,556)\end{array}$ \\
\hline \multirow[t]{2}{*}{ Gender, \% } & Male & 53.6 & 54.4 & 51.9 & 51.6 & 52.3 \\
\hline & Female & 46.4 & 45.6 & 48.1 & 48.4 & 47.7 \\
\hline Age, years & Mean \pm SD & $62.0 \pm 13.3$ & $62.7 \pm 13.2$ & $63.6 \pm 13.4$ & $64.5 \pm 13.4$ & $65.2 \pm 13.2$ \\
\hline \multirow{6}{*}{ Age group, $\%$} & $18-34$ years & 3.7 & 3.7 & 3.6 & 3.4 & 3.0 \\
\hline & $35-44$ years & 7.4 & 6.9 & 6.6 & 6.1 & 5.7 \\
\hline & $45-54$ years & 12.6 & 12.0 & 11.0 & 10.7 & 10.1 \\
\hline & 55-64 years & 30.7 & 28.4 & 25.5 & 21.7 & 20.5 \\
\hline & $65-74$ years & 28.6 & 30.4 & 32.7 & 35.6 & 36.4 \\
\hline & $\geq 75$ years & 17.0 & 18.6 & 20.6 & 22.5 & 24.3 \\
\hline
\end{tabular}

$\mathrm{CHB}$, chronic hepatitis $\mathrm{B}$; $\mathrm{SD}$, standard deviation.

culate the mean, per-patient CCI score for each year, accompanied by the SD. The median and interquartile range (IQR) were also reported for each year. We also assessed the prevalence of 47 preselected comorbidities, based on ICD-10 codes [18, 19]. With regard to bone fracture data, patients may have both pathological and nonpathological bone fractures within a year and therefore be included separately in these subgroups, but only counted once in the "bone fracture (all)" category.

We assessed all-cause healthcare resource utilization and costs for each calendar year using derivations in Act data (online suppl. Table 2). In brief, we assessed the per-patient, per-year, all-cause healthcare resource utilization for each calendar year as given below. Patients who had no claim for any of these healthcare visits were assumed to have not utilized that resource:

- Number of patients with at least 1 inpatient admission.

- Mean, SD, median, and IQR of the number and duration of inpatient admissions.

- Number of patients with at least 1 outpatient visit to the hospital.

- Mean, SD, median, and IQR of the number of outpatient visits. For all-cause healthcare costs, we calculated the per-patient, per-year, mean, SD, median, and IQR of total and yearly healthcare costs, as well as costs of inpatient visit, outpatient visit, pharmacy or medication use, and diagnostic tests (including imaging, pathology, and laboratory tests) for each calendar year by adding up the cost reported for each patient and then dividing this sum by the number of patients who had claims in that calendar year. We categorized inpatient or outpatient resources based on the claims code assigned for each procedure within the MDV database (online suppl. Table 2). Inpatient costs refer to any costs associated with an inpatient stay in the hospital, including physician fees, accommodation costs, drug costs, and diagnostic tests, similarly for outpatient costs. Pharmacy costs and diagnostic costs include costs within these categories incurred in both the inpatient and outpatient setting. We did not adjust for inflation as the Japanese core inflation rate was approximately $0.7 \%$ between 2012 and 2016 [20].

Comparison tests were conducted for CCI scores, prevalence of the preselected comorbidities, and healthcare resource utilization and costs to compare the differences between results in 2012 and 2016. As samples in those 2 years were neither totally independent nor totally dependent, partially overlapping comparison tests were conducted [21]. The partially overlapping $t$ test was used for CCI score, healthcare resource utilization, and costs while the partially overlapping z-test was used for prevalence of each preselected comorbidity. A $p$ value of $<0.05$ was considered statistically significant.

\section{Results}

\section{Patient Characteristics}

A total of 11,125 CHB patients met the eligibility criteria and were included in the analysis; the application of the exclusion criteria to derive the patient population is detailed in online suppl. Table 3. The number of patients included in each year increased substantially, predominantly reflecting increased inclusion of centers within the MDV database over time. Around half (52-54\%) of the cohort were male (Table 1). The mean age of our CHB cohort increased from 62.0 years in 2012 to 65.2 years in 2016 (Table 1). The proportion of senior citizens (aged $\geq 65$ years) increased from $45.6 \%$ in 2012 to $60.7 \%$ in 2016 (Table 1). The proportion of very elderly patients aged $\geq 75$ years also increased from $17.0 \%$ in 2012 to $24.3 \%$ in 2016 (Table 1).

\section{Comorbidity Burden}

Across each calendar year, we were able to estimate CCI scores for $>96 \%$ of included patients. The mean CCI score per patient increased from 4.0 in 2012 to 4.8 in 2016, while the median score increased from 3.0 to 4.0 (Fig. 1).

The prevalence of the 47 selected comorbidities is presented in Table 2. From 2012 to 2016, the prevalence of 
Fig. 1. Mean and median Charlson Comorbidity Index (CCI) score in the study population by calendar year.

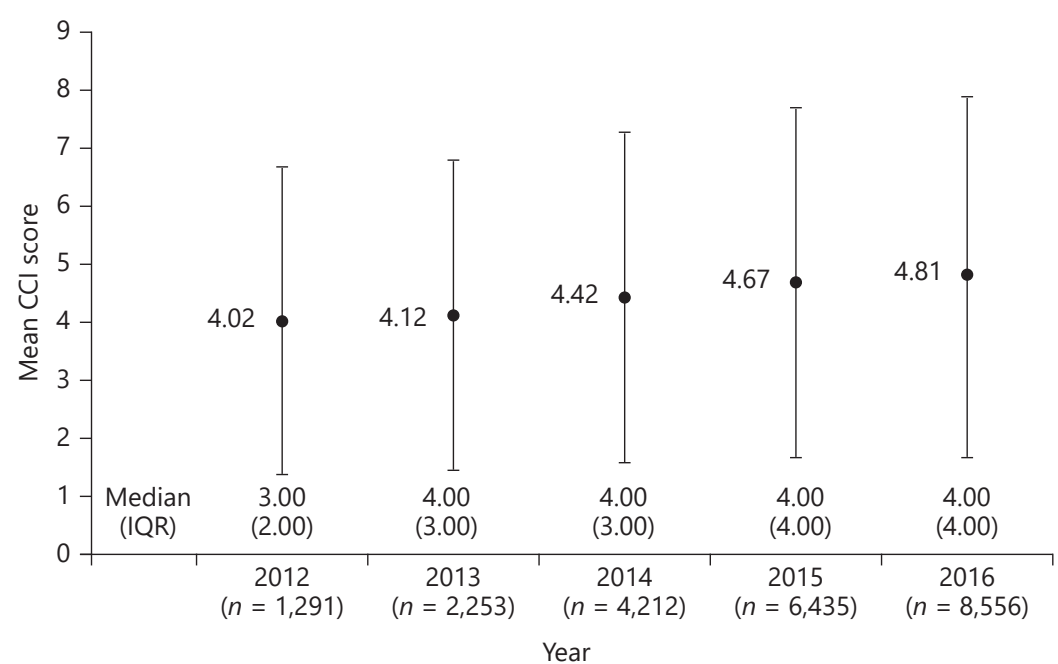

most comorbidities increased significantly. While total cancer cases increased significantly over time (from $40.9 \%$ to $52.0 \%, p<0.01$ ), the prevalence of HCC decreased significantly, from $6.3 \%$ in 2012 to $4.5 \%$ in 2016 $(p<0.01)$, and the prevalence of cirrhosis remained stable across the period, at 5.8\% in 2012 and 5.6\% in 2016 ( $p=$ $0.69)$. Other liver diseases, including nonalcoholic fatty liver disease/hepatic steatosis (2012: 3.7\%; 2016: 4.1\%, $p=0.44)$ and alcoholic liver disease/alcoholic cirrhosis/ alcoholic hepatitis (2012: 1.4\%; 2016: 1.7\%, $p=0.45)$, also remained stable.

The prevalence of osteoporosis increased significantly from $12.1 \%$ to $17.7 \%(p<0.01)$ over time, with significant increases also seen in the occurrence of bone fractures $(3.1-4.6 \%, p=0.01)$. Significantly more patients experienced renal impairment in 2016 compared to 2012 (increase from $10.7 \%$ to $15.0 \%, p<0.01$ ), driven partially by a significant increase in cases of chronic kidney disease (from $3.4 \%$ to $5.6 \%, p<0.01$ ) (Table 2 ).

\section{All-Cause Healthcare Resource Use}

Across all calendar years, roughly one-third of $\mathrm{CHB}$ patients had at least 1 inpatient admission (due to any cause) and the mean, per-patient number of inpatient admissions per year increased from 0.58 in 2012 to 0.70 in $2016(p<0.01)$ (Table 3). The mean, per-patient duration of inpatient admission increased slightly from 9 to 11 days from 2012 to 2016 ( $p=0.09)$. The median number of inpatient admissions and median duration of inpatient admissions were zero across all years, as two-thirds of patients were not admitted as inpatients. The vast majority
( $\geq 89 \%$ ) of all CHB patients had at least 1 outpatient visit each year, and the mean per-patient number of outpatient visits per year increased from 7.4 in 2012 to 12.0 in 2016 $(p<0.01)$. The median number of outpatient visits doubled in the same time period (from 4.0 in 2012 to 8.0 in 2016) (Table 3).

\section{All-Cause Healthcare Costs}

From 2012 to 2016, the mean total healthcare costs per patient per year increased from JPY 846,178 to 1,332,417 $(p<0.01)$. The median total healthcare costs increased from JPY 229,143 to 502,467 (Table 4). In 2012 and 2013, inpatient costs represented a larger component of the total healthcare costs as compared to outpatient costs. However, by 2016, the mean outpatient cost was JPY 711,523 per patient per year, while the mean per-patient inpatient cost was JPY 621,894 (Table 4). The per-patient drug cost increased significantly between 2012 and 2016 . Diagnostic costs remained the smallest cost component across all years, although these also increased significantly (Table 4).

\section{Discussion/Conclusion}

This large real-world analysis has helped to characterize and assess the changes over time of the demographics, comorbidities, and healthcare resource utilization and costs of $\mathrm{CHB}$ patients in Japan. Our study showed that the majority of $\mathrm{CHB}$ patients in Japan are elderly, with a mean age of 65 years and with $61 \%$ being $\geq 65$ years old in 


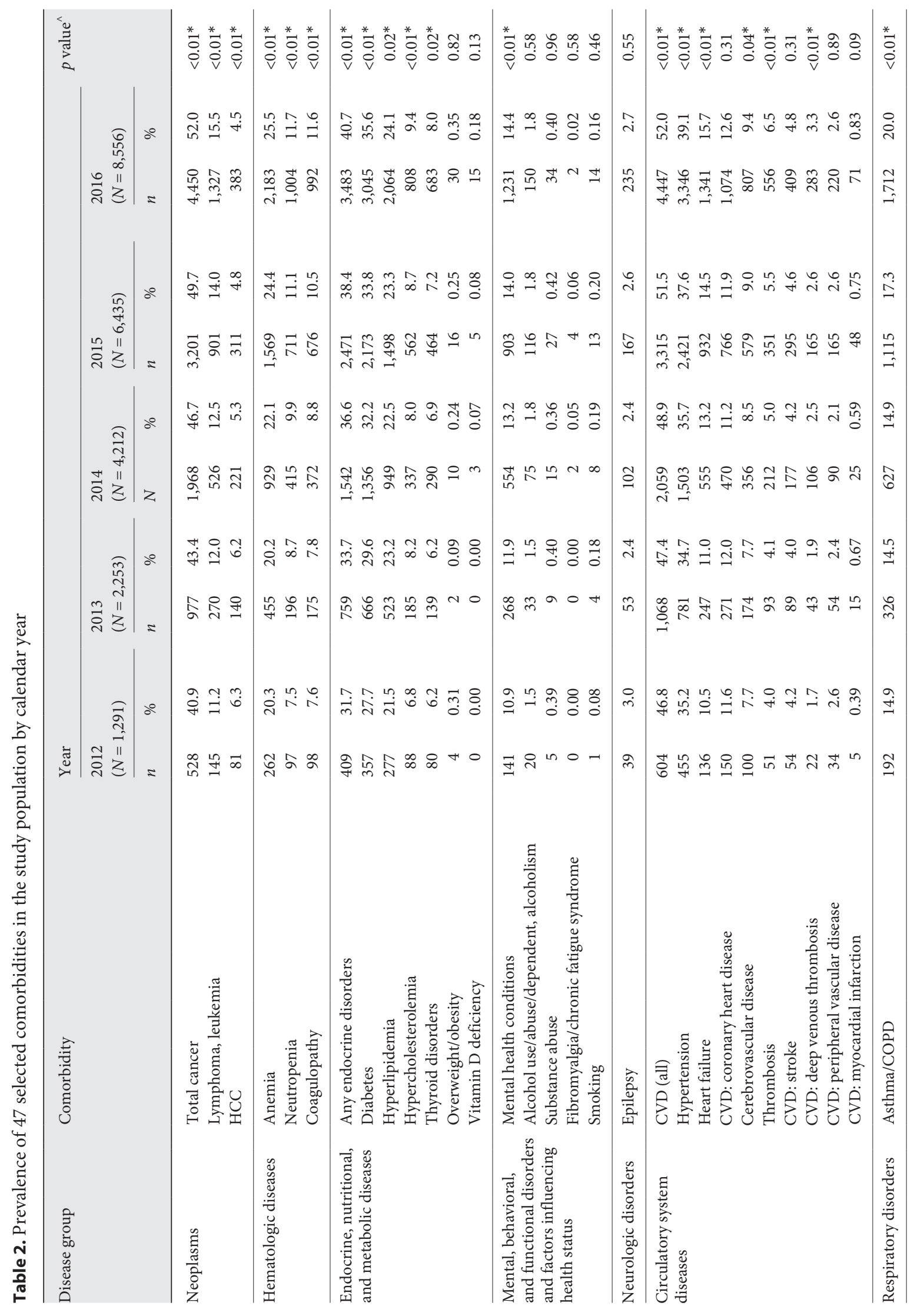




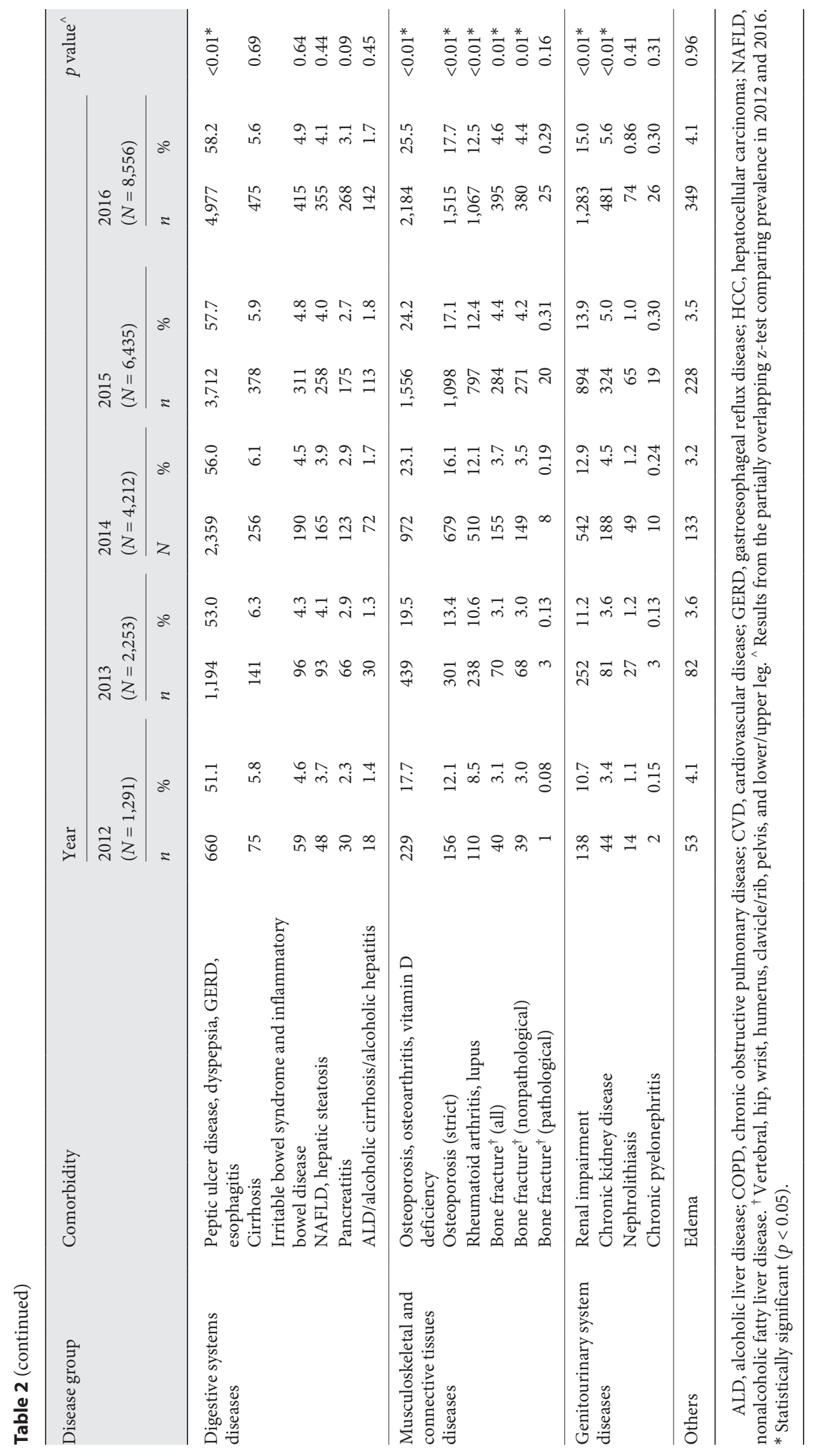


Table 3. All-cause healthcare resource utilization of the study population by calendar year

\begin{tabular}{|c|c|c|c|c|c|c|}
\hline & $\begin{array}{l}2012 \\
(N=1,291)\end{array}$ & $\begin{array}{l}2013 \\
(N=2,253)\end{array}$ & $\begin{array}{l}2014 \\
(N=4,212)\end{array}$ & $\begin{array}{l}2015 \\
(N=6,435)\end{array}$ & $\begin{array}{l}2016 \\
(N=8,556)\end{array}$ & $p$ value ${ }^{\wedge}$ \\
\hline$N(\%)$ & $458(35.5)$ & $784(34.8)$ & $1,526(36.2)$ & $2,377(36.9)$ & $3,089(36.1)$ & \\
\hline \multicolumn{7}{|c|}{ Inpatient admissions, $n$} \\
\hline Mean \pm SD & $0.58 \pm 1.1$ & $0.60 \pm 1.1$ & $0.67 \pm 1.3$ & $0.71 \pm 1.4$ & $0.70 \pm 1.4$ & $<0.01^{*}$ \\
\hline \multicolumn{7}{|c|}{ Duration of inpatient admission, days } \\
\hline Mean $\pm \mathrm{SD}$ & $9.3 \pm 24.3$ & $10.1 \pm 24.4$ & $9.8 \pm 23.0$ & $10.9 \pm 25.6$ & $10.6 \pm 25.2$ & \multirow{2}{*}{0.09} \\
\hline Median \pm IQR & $0.0 \pm 7.0$ & $0.0 \pm 8.0$ & $0.0 \pm 8.0$ & $0.0 \pm 9.0$ & $0.0 \pm 8.0$ & \\
\hline \multicolumn{7}{|c|}{ Patients with at least 1 outpatient visit, $n$} \\
\hline$N(\%)$ & $1,150(89.1)$ & $2,194(97.4)$ & $4,109(97.6)$ & $6,281(97.6)$ & $8,376(97.9)$ & \\
\hline \multicolumn{7}{|l|}{ Outpatient visits, $n$} \\
\hline Mean \pm SD & $7.4 \pm 12.4$ & $10.6 \pm 13.2$ & $11.1 \pm 13.2$ & $11.6 \pm 13.9$ & $12.0 \pm 14.2$ & $<0.01^{*}$ \\
\hline
\end{tabular}

$N$, total population in the year of interest; $n$, number of patients who had at least 1 claim for the corresponding resource; IQR, interquartile range; $\mathrm{SD}$, standard deviation. ${ }^{\wedge}$ Results from the partially overlapping $t$ test comparing difference in mean values in 2012 and 2016. * Statistically significant.

Table 4. All-cause healthcare costs among the study population by calendar year

\begin{tabular}{|c|c|c|c|c|c|c|}
\hline & $\begin{array}{l}2012 \\
(N=1,291)\end{array}$ & $\begin{array}{l}2013 \\
(N=2,253)\end{array}$ & $\begin{array}{l}2014 \\
(N=4,212)\end{array}$ & $\begin{array}{l}2015 \\
(N=6,435)\end{array}$ & $\begin{array}{l}2016 \\
(N=8,556)\end{array}$ & $p$ value \\
\hline \multicolumn{7}{|c|}{ Total healthcare costs, JPY } \\
\hline Median $\pm \mathrm{IQR}$ & $229,143 \pm 853,426$ & $399,655 \pm 1,139,165$ & $435,384 \pm 1,276,873$ & $489,058 \pm 1,487,444$ & $502,467 \pm 1,540,814$ & $<0.01^{*}$ \\
\hline \multicolumn{7}{|l|}{ Inpatient costs, JPY } \\
\hline Mean \pm SD & $496,755 \pm 1,232,022$ & $534,012 \pm 1,358,322$ & $538,055 \pm 1,231,344$ & $623,209 \pm 1,471,906$ & $621,894 \pm 1,463,743$ & $<0.01^{*}$ \\
\hline \multicolumn{7}{|l|}{ Outpatient costs, JPY } \\
\hline Mean \pm SD & $349,423 \pm 782,989$ & $511,411 \pm 899,423$ & $554,160 \pm 930,093$ & $638,039 \pm 1,155,284$ & $711,523 \pm 1,283,907$ & \multirow{2}{*}{$<0.01^{*}$} \\
\hline Median \pm IQR & $106,878 \pm 278,263$ & $202,918 \pm 491,111$ & $219,100 \pm 511,608$ & $240,129 \pm 559,920$ & $270,402 \pm 601,592$ & \\
\hline \multicolumn{7}{|c|}{ Pharmacy/drug costs, JPY } \\
\hline Mean \pm SD & $331,798 \pm 740,431$ & $462,680 \pm 1,002,037$ & $489,395 \pm 933,362$ & $581,985 \pm 1,202,836$ & $633,063 \pm 1,306,028$ & \multirow{2}{*}{$<0.01^{*}$} \\
\hline Median \pm IQR & $63,972 \pm 276,426$ & $119,555 \pm 448,040$ & $130,413 \pm 472,314$ & $149,040 \pm 540,375$ & $163,614 \pm 563,428$ & \\
\hline \multicolumn{7}{|c|}{ Diagnostic test costs, JPY } \\
\hline
\end{tabular}

IQR, interquartile range; JPY, Japanese yen; SD, standard deviation. ${ }^{\wedge}$ Results from the partially overlapping $t$ test comparing difference in mean costs in 2012 and 2016. *Statistically significant.

2016 compared with $46 \%$ of patients in 2012 . While the trend of advancing age has been observed in CHB patients from recent studies around the world, the mean age of our study population was approximately 10 to almost 16 years higher than $\mathrm{CHB}$ population in the USA ( $51.8 \pm$ 12.4 years in 2015) and neighboring Asian countries such as Korea (49.5 \pm 9.4 in 2015) and Hong Kong (55 \pm 15 in 2014-2017) [12, 22, 23]. Though Japan, as a whole, has an aging population, the $\mathrm{CHB}$ patient population is on average substantially older than the general population: $23.4 \%$ of the population in Japan was $\geq 65$ years old in $2012 \mathrm{com}-$ pared with $45.6 \%$ of patients in our study for the same year [24]. This differential age distribution is likely due to the implementation of hepatitis $B$ vaccination programs started in the late 1980s, which essentially eliminated $\mathrm{HBV}$ infections in patients under the age of 30 . Unlike the 
USA, where the majority of CHB cases are "imported" due to steady immigration from endemic countries, the immigrant population of Japan remains low at $2 \%$ over the past decade [25]. The use of antiviral treatment, which reduces the risk of disease progression (as potentially reflected by the decreasing prevalence of HCC and steady prevalence of cirrhosis observed in this study), may also help prolong the life expectancy of $\mathrm{CHB}$ patients and contribute to the aging of the $\mathrm{CHB}$ population [26-28].

Another reason for the advanced age of $\mathrm{CHB}$ patients in Japan and elsewhere in the world can be due to delayed screening and diagnosis, such that HBV-infected patients do not get diagnosed until later in life. Indeed, the connection to care for $\mathrm{CHB}$ patients is suboptimal, even in high-income countries, as illustrated by a $15 \%$ liver disease awareness rate in a recent population-based survey study and a 19\% CHB diagnosis rate among 198 million Americans with private insurance $[29,30]$.

While the general trend in our study was an increase in the prevalence of comorbidities, we reported a decreasing trend of cirrhosis and HCC. This result is in line with other studies from Japan showing a decreasing contribution of viral hepatitis to overall national cirrhosis and HCC cases, with CHB-related cirrhosis cases dropping from $11.6 \%$ of overall cirrhosis cases in 2008 to $8.8 \%$ in $2016[31,32]$. This may reflect improvements in CHB treatment over the past decade.

With a rapidly aging $\mathrm{CHB}$ population in our study, it is unsurprising that the prevalence of most nonliver comorbidities increased over time. This is an important finding for clinicians to consider during the course of the management and monitoring of these patients. In fact, our comorbidity analyses demonstrated that the mean CCI score of $\mathrm{CHB}$ patients in the present study increased by almost 1 point, from 4.0 in 2012 to 4.8 in 2016. In addition, as with the mean age discussed above, the mean CCI was higher among the CHB population of this study than in a 2015 study from the USA $(2.6 \pm 3.0$ among Medicaid patients) [12].

Somewhat daunting is that by 2016 , the majority of the Japanese CHB population in this study had gastroesophageal diseases $(58.2 \%)$, cancer (52.0\%), or CVD (52.0\%) while approximately one-third had hypertension (39.1\%) or diabetes (35.6\%). All of these comorbidities were substantially higher than the prevalence of any malignancy, CVD, hypertension, and diabetes findings from the USA $(7.3 \%, 11.8 \%, 32.0 \%$, and $15.3 \%$, respectively, in 2015$)$ or Hong Kong (23.6\%, 22.2\%, 28.6\%, and 20.1\%, respectively, in 2014-2017) studies [12,23]. The results likely reflect the particularly aged nature of the $\mathrm{CHB}$ population in Ja- pan, with the hypertension prevalence $(39.1 \%)$ being similar to that reported in 2016 for Japanese women aged 50-59 years (35.7\%) [33]. However, the diabetes prevalence $(35.6 \%)$ in our study is much higher than in the general Japanese population (8.3-16\%) [34]. These discrepancies could be due to surveillance bias in which people with one chronic disease such as $\mathrm{CHB}$ undergo more screening and surveillance for other comorbidities.

Approximately one-quarter (25.5\%) of the studied CHB population also had bone-related diseases (osteoporosis, osteoarthritis, or vitamin D deficiency) and 15.0\% exhibited renal impairment of some degree. $\mathrm{CHB}$ patients with bone and renal disorders or patients who are at risk of such impairments may require special considerations such as medication dosage adjustment and/or avoidance of antiviral medications that can compromise bone or renal health, as per international CHB management guidelines $[35,36]$.

We observed an increase in resource utilization and costs in our study cohort over time, a finding that is consistent with data from other countries [37, 38]. By 2016, median all-cause healthcare costs among $\mathrm{CHB}$ patients in this study were JPY 502,467 , translating to a $119.3 \%$ increase from JPY 229,143 in 2012. This rise in costs corresponds with a rise in the utilization of healthcare resources, including the number of both inpatient admissions and outpatient visits. However, we caution against interpretation that the rising cost was due solely to $\mathrm{CHB}$, as our analysis considered all costs incurred by $\mathrm{CHB}$ patients, not only CHB-related costs.

Apart from the limitations already highlighted, the study has further limitations pertaining to the use of the MDV database. Despite the increasing coverage of the database, patients may have also sought care at facilities not covered by the MDV database used in this study, though this is unlikely since patients with chronic conditions tend to follow-up with their regular physician. In addition, the MDV database only covers certain medical centers that include both acute care hospitals and outpatient clinics. Thus, our analyses did not capture any resource use or costs of CHB patients managed in other types of healthcare facilities such as ambulatory centers or primary care facilities, if they were not attached to acute care hospitals. Any effect is likely to be limited, as specialized medical institutions are appointed as the primary care provider for viral hepatitis patients in Japan [9]. The MDV database does not include clinical or laboratory data for the vast majority of patients; as such, we were unable to characterize the clinical and laboratory characteristics of our study population or investigate their potential associations with study outcomes. Similarly, the lack of clinical data to ad- 
just for background differences between the treated and untreated groups also limited our ability to investigate the effect of antiviral therapy on study outcomes. Finally, we excluded data prior to 2012 from our study, due to unstable fluctuations in patient demographics. Nevertheless, even the 2012 data may be subject to such fluctuations, as potentially indicated by the $8 \%$ increase in patients attending outpatient visits between 2012 and 2013. Therefore, the 2012 data should be interpreted with caution.

In conclusion, the $\mathrm{CHB}$ patient population in Japan is elderly with an advancing mean age. Between 2012 and 2016, 61\% were aged 65 years or older and 1 in 4 were aged 75 years or older by 2016. Over this time period, liver-related morbidities decreased but the nonliver comorbidity burden increased; by 2016, more than half of the study population presented with cancer or CVD, onethird with diabetes, one-third with hypertension, onequarter with bone disorders, and 15\% with renal impairment. Assessment and consideration of these highly prevalent and relevant nonliver comorbidities are important in this elderly $\mathrm{CHB}$ population.

\section{Acknowledgements}

Writing assistance was provided by Min Hee Choi, $\mathrm{PhD}$, of Costello Medical, Singapore. Database analysis support was provided by Tristan Curteis and Amy Buchanan-Hughes of Costello Medical, UK.

\section{Statement of Ethics}

Ethics committee approval for this study was not required. Patient data in the Medical Data Vision (MDV) are deidentified at the hospital level before being incorporated into the database, and the medical claims data retrieved from the database for this study were unlinkable to individual patients. Furthermore, there was no active enrollment, interventions, follow-up, or direct data collection from individuals.

\section{Conflict of Interest Statement}

Hiroshi Yotsuyanagi has received consultation fee from Gilead Sciences and lecture fee from Gilead Sciences, MSD, and BMS. Masayuki Kurosaki has received consultation fees from Gilead and speaker's fee from Gilead, MSD, AbbVie, Eisai, Shionogi, and Bayer. Hiroshi Yatsuhashi has received research support from AbbVie. I-Heng Lee is an employee of Gilead Sciences. Alvin Ng and Craig Brooks-Rooney are employees of Costello Medical, which was funded by Gilead Sciences to provide research, writing, and editorial services for this manuscript. Mindie H. Nguyen has received research support from Gilead Sciences, Pfizer, Glycotest, Vir, Enanta, National Cancer Institute, and B.K. Kee Foundation and has served as an advisory board member or consultant for Gilead, Intercept, Novartis, Spring Bank, Exact Sciences, Laboratory of Advanced Medicine, Eisai, Bayer, and Janssen.

\section{Funding Sources}

This study was funded by Gilead Sciences Inc.

\section{Author Contributions}

Mindie H. Nguyen, I-Heng Lee, and Craig Brooks-Rooney designed the study. Craig Brooks-Rooney and Alvin Ng analyzed the data. Mindie H. Nguyen participated in the drafting of the manuscript. Hiroshi Yotsuyanagi provided input during study design, interpretation of the data, and drafting of the manuscript. All authors critically reviewed and contributed to the revision of the manuscript. All authors have read and approved the final version of the manuscript.

\section{References}

1 World Health Organization. Hepatitis B. [cited $2020 \mathrm{Feb}$. Available from: https://www. who.int/news-room/fact-sheets/detail/hepatitis-b.

2 Razavi-Shearer D, Gamkrelidze I, Nguyen $\mathrm{MH}$, Chen D-S, Van Damme P, Abbas Z, et al. Global prevalence, treatment, and prevention of hepatitis B virus infection in 2016: a modelling study. Lancet Gastroenterol Hepatol. 2018;3(6):383-403.

3 Coalition for Global Hepatitis Elimination. Country Profiles, Japan. [cited 2020 Jan]. Available from: https://www.globalhep.org/ country-progress/japan.

4 Tanaka J, Akita T, Ohisa M, Sakamune K, Ko K, Uchida S, et al. Trends in the total numbers of HBV and HCV carriers in Japan from 2000 to 2011. J Viral Hepat. 2018; 25(4):363-72.

5 Ujiie M, Sasaki K, Yoshikawa N, Enami T, Shobayashi T. Introduction of a hepatitis B vaccine into the national routine immunisation programme of Japan. Lancet Infect Dis. 2016;16(12):1325.

6 OECD. Life expectancy at 65 (indicator). [cited 2019 Dec]. Available from: https://www. oecd-ilibrary.org/social-issues-migrationhealth/life-expectancy-at-65/indicator/ english_0e9a3f00-en.

7 OECD. Fertility rates (indicator). [cited 2019 Dec]. Available from: https://www.oecd-ilibrary.org/social-issues-migration-health/ fertility-rates/indicator/english_8272fb01en.

8 Statistics Bureau, Ministry of Internal Affairs and Communications, Japan. Japan Statistical Yearbook 2020. [cited 2019 Dec]. Available from: http://www.stat.go.jp/english/data/ nenkan/69nenkan/index.html.

9 Oza N, Isoda H, Ono T, Kanto T. Current activities and future directions of comprehensive hepatitis control measures in Japan: The supportive role of the hepatitis information center in building a solid foundation. Hepatol Res. 2017;47(6):487-96.

10 Worldometer. GDP by Country. [cited 2021 Jan]. Available from: https://www.worldometers.info/gdp/gdp-by-country/. 
11 Worldometer. Countries in the world by population (2021). [cited $2021 \mathrm{Jan}$ ]. Available from: https: //www.worldometers.info/ world-population/population-by-country/.

12 Nguyen MH, Lim JK, Burak Ozbay A, Fraysse J, Liou I, Meyer N, et al. Advancing age and comorbidity in a US insured populationbased cohort of patients with chronic hepatitis B. Hepatology. 2019;69(3):959-73.

13 Nguyen MH, Burak Ozbay A, Liou I, Meyer N, Gordon SC, Dusheiko G, et al. Healthcare resource utilization and costs by disease severity in an insured national sample of US patients with chronic hepatitis B. J Hepatol. 2019;70(1):24-32.

14 Chen YC, Su YC, Li CY, Hung SK. 13-year nationwide cohort study of chronic kidney disease risk among treatment-naïve patients with chronic hepatitis B in Taiwan. BMC Nephrol. 2015;16:110.

15 Medical Data Vision. Clinical Database Overview (as of November 30, 2017) The number of the patients is 208,00,000. [cited $2019 \mathrm{Aug}$ ]. Available from: https://www.mdv.co.jp/ press/2017/detail_891.html.

16 Statistics Japan. Senior Citizens. [cited 2019 Dec]. Available from: https://stats-japan. com/t/kiji/12053.

17 Quan H, Li B, Couris CM, Fushimi K, Graham $\mathrm{P}$, Hider $\mathrm{P}$, et al. Updating and validating the Charlson comorbidity index and score for risk adjustment in hospital discharge abstracts using data from 6 countries. Am J Epidemiol. 2011;173(6):676-82.

18 Sato M, Ye W, Sugihara T, Isaka Y. Fracture risk and healthcare resource utilization and costs among osteoporosis patients with type 2 diabetes mellitus and without diabetes mellitus in Japan: retrospective analysis of a hospital claims database. BMC Musculoskelet Disord. 2016;17(1):489.

19 World Health Organization. ICD-10 Version: 2016. [cited 2020 Feb]. Available from: https: //icd.who.int/browse10/2016/en.

20 Statista. Japan: Inflation rate from 1984-2020. [cited $2020 \mathrm{Feb}$ ]. Available from: https:// www.statista.com/statistics/270095/inflation-rate-in-japan/.
21 Derrick B, Russ B, Toher D, White P. Test statistics for the comparison of means for two samples that include both paired and independent observations. J Mod App Stat Meth. 2017;16(1):137-57.

22 Kim SE, Jang ES, Ki M, Gwak GY, Kim KA, Kim GA, et al. Chronic hepatitis B infection is significantly associated with chronic kidney disease: a population-based, matched casecontrol study. J Korean Med Sci. 2018;33(42): e264.

23 Wong GL, Wong VW, Yuen BW, Tse YK, Luk HW, Yip TC, et al. An aging population of chronic hepatitis B with increasing comorbidities: a territory-wide study from 2000 to 2017. Hepatology. 2019;71(2):444-55.

24 ILC-Japan. A Profile of Older Japanese 2013. [cited 2019 Sept]. Available from: http:// www.ilcjapan.org/agingE/POJ13.html.

25 Statista. Japan: Total number of registered foreign residents living in Japan from 2009 to 2018 (in millions). [cited 2021 Jan]. Available from: https: //www.statista.com/statistics/687809/japan-foreign-residents-totalnumber/.

26 Marcellin P, Gane E, Buti M, Afdhal N, Sievert W, Jacobson IM, et al. Regression of cirrhosis during treatment with tenofovir disoproxil fumarate for chronic hepatitis B: a 5-year open-label follow-up study. Lancet. 2013; 381(9865):468-75.

27 Papatheodoridis GV, Idilman R, Dalekos GN Buti $\mathrm{M}$, Chi $\mathrm{H}$, van Boemmel F, et al. The risk of hepatocellular carcinoma decreases after the first 5 years of entecavir or tenofovir in Caucasians with chronic hepatitis B. Hepatology. 2017;66(5):1444-53.

28 Yip TC, Wong GL, Chan HL, Tse YK, Lam KL, Lui GC, et al. HBsAg seroclearance further reduces hepatocellular carcinoma risk after complete viral suppression with nucleos $(\mathrm{t})$ ide analogues. J Hepatol. 2019;70(3):361-70.
29 Le MH, Yeo YH, Cheung R, Henry L, Lok AS, Nguyen MH. Chronic hepatitis B prevalence among foreign-born and U.S.-born adults in the United States, 1999-2016. Hepatology. 2020;71(2):431-43

30 Ogawa E, Yeo YH, Dang N, Le MH, Jeong D, Tran S, et al. Diagnosis rates of chronic hepatitis B in Privately insured patients in the United States. JAMA Netw Open. 2020;3(4): e201844-e.

31 Enomoto H, Ueno Y, Hiasa Y, Nishikawa $\mathrm{H}$, Hige S, Takikawa Y, et al. Transition in the etiology of liver cirrhosis in Japan: a nationwide survey. J Gastroenterol. 2020;55(3):35362.

32 Tateishi R, Uchino K, Fujiwara N, Takehara $\mathrm{T}$, Okanoue T, Seike M, et al. A nationwide survey on non- $\mathrm{B}$, non-C hepatocellular carcinoma in Japan: 2011-2015 update. J Gastroenterol. 2019;54(4):367-76.

33 Hisamatsu T, Segawa H, Kadota A, Ohkubo T, Arima H, Miura K. Epidemiology of hypertension in Japan: beyond the new 2019 Japanese guidelines. Hypertens Res. 2020;43(12): 1344-51.

34 Ikeda N, Nishi N, Noda H, Noda M. Trends in prevalence and management of diabetes and related vascular risks in Japanese adults: Japan National Health and Nutrition Surveys 2003-2012. Diabetes Res Clin Pract. 2017 127:115-22.

35 European Association for the Study of the Liver. EASL 2017 clinical practice guidelines on the management of hepatitis B virus infection. J Hepatol. 2017;67(2):370-98.

36 Terrault NA, Lok ASF, McMahon BJ, Chang KM, Hwang JP, Jonas MM, et al. Update on prevention, diagnosis, and treatment of chronic hepatitis B: AASLD 2018 hepatitis B guidance. Hepatology. 2018;67(4):1560-99.

37 Baik D, Kim BW, Oh JK, Kim KA, Ki M. Costs of viral hepatitis B in the Republic of Korea, 2002-2015. J Viral Hepat. 2020;27(2):156-67.

38 Park H, Jeong D, Nguyen P, Henry L, Hoang $\mathrm{J}$, Kim Y, et al. Economic and clinical burden of viral hepatitis in California: A populationbased study with longitudinal analysis. PLoS One. 2018;13(4):e0196452. 